\title{
Lagoas de polimento operando em bateladas como pós-tratamento de reatores UASB: remoção de material orgânico
}

\section{Polishing ponds operating in batch mode for post treatment of UASB reactors: organic material removal}

Data de entrada: 02/06/2019

- Data de aprovação: $18 / 06 / 2020$

Mateus Rodrigues Lima Aguiar ${ }^{1}$ | Silvânia Lucas dos Santos ${ }^{2}$ | Adrianus van Haandel ${ }^{1 *}$

DOI: https://doi.org/10.36659/dae.2021.020

ORCID ID

Aguiar MRL (D) https://orcid.org/0000-0003-2101-4703
Santos SL (iD https://orcid.org/0000-0002-6905-3966 Haandel A (D) https://orcid.org/0000-0002-9937-6715

\section{Resumo}

O regime de bateladas sequenciais em lagoas de polimento apresenta duas vantagens importantes em relação às lagoas de fluxo contínuo: (1) reduz consideravelmente o tempo necessário para a remoção bacteriana e (2) possibilita a remoção eficiente dos nutrientes nitrogênio e fósforo. Entretanto, a aplicabilidade do regime de bateladas sequenciais é limitada pela concentração de material orgânico no afluente da lagoa: se essa concentração é alta, a demanda por oxigênio excede a capacidade de geração na lagoa e o ambiente fica anaeróbio, o que é indesejável, pois a digestão anaeróbia deixa um residual de material orgânico alto. Nesse contexto, este trabalho teve como objetivo avaliar a remoção do material orgânico residual do efluente pré-tratado anaerobiamente (reator UASB) em lagoas de polimento operadas em regime de bateladas sequenciais. Além disso, avaliou-se a influência da concentração inicial do material orgânico e da profundidade no desempenho das lagoas. A operação das lagoas de polimento permitiu a remoção eficiente da DBO (em média 70\%), mas o tempo para alcançar a DBO mínima aumentou com a profundidade. Durante o tratamento, a DBO passou por um mínimo e depois aumentou presumivelmente devido à produção de algas. Em todos os casos, quando a DBO do afluente da lagoa aumentou, a concentração mínima do efluente também aumentou.

Palavras-chave: Pré-tratamento anaeróbio. Remoção da DBO. Profundidade da lagoa.

\section{Abstract}

The sequential batch regime in polishing ponds has two important advantages in relation to continuous flow ponds: (1) it greatly reduces the time required for bacterial removal and (2) it opens the possibility of efficiently removing the nutrients nitrogen and phosphorus. However, the applicability of the sequential batch regime is limited by the concentration of organic material in the influent of the pond: if this concentration is too high, the oxygen demand exceeds the oxygen generation capacity in the pond and the environment remains anaerobic, which is undesirable: the anaerobic digestion leaves a high concentration of residual organic material. In this context, this work aims to evaluate the removal of residual organic material from the effluent of a UASB reactor in polishing ponds operated in sequential batch mode. In addition, the influence of the initial concentration of organic material and depth on the performance of the ponds was evaluated. The operation of polishing ponds in sequential batches allowed efficient

\footnotetext{
${ }^{1}$ Universidade Federal de Campina Grande - UFCG - Campina Grande - Paraíba - Brasil.

${ }^{2}$ Universidade Federal do Rio Grande do Norte - UFRN - Rio Grande do Norte - Brasil.

"Autor correspondente: adrianusvhagmail.com.
} 
removal of organic material, $B O D$ (on average $70 \%$ ), but the time to reach the minim DBO increased with increasing depth. During the treatment of a batch, the BOD went through a minimum and then increased, presumably due to the production of algae. In all cases, when the organic material concentration applied in the LPBS increased, the concentration of the minimum residual BOD also increased.

Keywords: Anaerobic Pretreatment. BOD removal efficiency. Pond depth.

\section{INTRODUÇÃO}

No início do século XX, constatou-se que os sistemas de tratamento primário operados até então não eram suficientes para a proteção dos recursos hídricos, tendo em vista as crescentes descargas de esgoto bruto ou parcialmente tratados. Assim, em pouco tempo, foram desenvolvidos sistemas de tratamento em nível secundário, para a remoção biológica de material orgânico, que na época era percebido como o principal (de fato o único) causador dos problemas ambientais. Além dos sistemas anaeróbios (Tanque Imhoff) e aeróbios (lodo ativado), surgiram também as lagoas de estabilização (LE). Dentre as configurações do sistema de lagoas, foi estabelecido que a melhor configuração para a remoção do material orgânico era a subdivisão em lagoas operadas em série, sendo: (1) Lagoa anaeróbia (LAn), uma lagoa relativamente pequena operando em ambiente anaeróbio onde o material orgânico era removido pela digestão anaeróbia; (2) Lagoa facultativa (LF), uma lagoa maior, em que o ambiente era parcialmente aeróbio devido à geração de oxigênio por algas que se desenvolviam na fase líquida, enquanto a parte inferior da lagoa era anaeróbia; e (3) Lagoa de maturação (LM), uma lagoa predominantemente aeróbia para a remoção de material orgânico residual e organismos patogênicos, principalmente bactérias do grupo coliformes e ovos de helmintos. Assim, ficou estabelecido o chamado sistema Australiano (PARKER et al., 1950), que continua sendo uma das configurações de projetos de lagoas mais utilizadas até o dia de hoje. A ideia básica do sistema Australiano é que a di- gestão anaeróbia é eficiente para a remoção de material orgânico quando sua concentração é elevada. Todavia, ao digerir o material orgânico a sua concentração diminui. Por essa razão, o tratamento anaeróbio ainda deixa uma concentração residual relativamente alta, que só pode ser reduzida em ambiente parcial ou predominantemente aeróbio.

O tratamento aeróbio, por sua natureza, deixa uma concentração de material orgânico residual baixa (VAN HAANDEL; VAN DER LUBBE, 2019). Por essa razão, a LF e as $L M$ devem ser ao menos parcialmente aeróbias. Portanto, o critério básico de projetos de lagoas de estabilização do tipo facultativa se baseia na premissa de que deve existir um equilíbrio entre a geração de oxigênio pelas algas e o consumo de oxigênio para a oxidação de material orgânico. Como a geração de oxigênio pelas algas é lenta, o tempo para manter o equilíbrio entre a produção e o consumo de oxigênio é longo e, consequentemente, o tempo de permanência na lagoa e a área per capita são consideráveis. Mara (1976) sugeriu uma área per capita de $1,5 \mathrm{~m}^{2}$ em $L M$, o que resulta num tempo de permanência de 30 dias, aproximadamente. Esse ambiente aeróbio tem por função principal a remoção de patógenos, mas também ocorre a remoção adicional de material orgânico.

Marais e Shaw (1961) mostraram que as lagoas de estabilização também podiam ser usadas para melhorar a qualidade higiênica do esgoto, pelo decaimento natural dos microrganismos. Os referidos autores concluíram ainda que o processo de decaimento pode ser modelado como uma 
reação de primeira ordem. Marais (1974) mostrou que, para o decaimento ser mais eficiente, era conveniente subdividir a $L M$ e operá-las em série. Desde então, não foram observados avanços no modelamento de LE. Para ter uma eficiência boa (99,9 a 99,99\% de remoção) na remoção de bactérias do grupo coliformes, necessária para reúso agrícola, as LM divididas (série de lagoas) precisam ter uma área da mesma ordem de grandeza que a LM única. É pouco provável que uma lagoa de maturação unitária, embora muito aplicada na prática, produza uma qualidade de efluente compatível com as exigências requeridas para irrigação.

Os objetivos do tratamento em LE continuam sendo basicamente os mesmos até hoje: a remoção de material orgânico e os patógenos. Embora alguns pesquisadores tenham realizado trabalhos para remoção de nutrientes (PANO; MIDDLEBROOKS, 1982), os resultados não têm sido satisfatórios, com eficiências de remoção de menos que $40 \%$ (BASTOS et al., 2014) para nitrogênio e $20 \%$ de fósforo (GOMES, 2000). A razão desse insucesso deve-se ao fato de que para a remoção de nutrientes é necessário que o pH aumente substancialmente na lagoa, e isso não acontece nas lagoas de estabilização justamente porque nestas existe um equilíbrio entre produção e consumo de oxigênio. Assim, todas as LEs do mundo produzem normalmente um efluente que não atende às normas para descarga destes em águas de superfície: os nutrientes do afluente permanecem praticamente inalterados. Via de regra, as exigências das legislações ambientais vigentes requerem uma qualidade de efluente que dificilmente podem ser alcançada em LE. Portanto, a rigor, efluentes das LE não deveriam ser lançados em águas de superfície.

A qualidade do efluente pode ser melhorada significativamente quando se substitui o tratamento anaeróbio realizado na LAn por um sistema que na época ainda não havia sido desen- volvido: o reator anaeróbio de fluxo ascendente e manta de lodo (do inglês Upflow Anaerobic Sludge Blanket - UASB), seguido por um pós-tratamento em lagoas de polimento (LP). Atualmente o reator UASB já está sendo amplamente utilizado em diferentes países do mundo e no Brasil, como demonstrado por Chernicharo et al. (2018), estando presente em $40 \%$ das 1.667 ETEs inventariadas nas regiões Sul, Sudeste e Centro-Oeste do país.

Cavalcanti (2003) mostrou que o UASB rotineiramente tem uma eficiência de remoção de material orgânico superior à combinação Lan-LF e que, no pós-tratamento em lagoas de polimento, a remoção de material orgânico residual é factível em alta taxa, tendo-se uma lagoa com um tempo de permanência menor que em LE convencionais. Embora a eficiência de remoção do material orgânico em reatores UASB seja superior àquela da combinação LAn-LF, a qualidade do efluente de reatores UASB normalmente não é compatível com as exigências ambientais do Brasil, para lançamento de efluentes e enquadramento dos cursos d'água, Resoluções $n^{\circ}$ 430/2011 e n³57/2005 do CONAMA, respectivamente (BRASIL, 2005 , 2011). Vários pesquisadores (VAN HAANDEL; LETTINGA, 1994) sugeriram o uso de lagoas de polimento como opção de pós-tratamento de efluentes do UASB. Invariavelmente, tem-se usando lagoas de fluxo contínuo como unidades de pós-tratamento.

Todavia, Cavalcanti (2003) mostrou que a combinação UASB-Lagoa de polimento de fluxo contínuo (LPFC) não pôde produzir um efluente compatível com as exigências estabelecidas, nem mesmo quando o projeto do pós-tratamento era otimizado para a remoção de nutrientes. Em particular, a remoção de fósforo era parcial ou insignificante.

Uma alternativa da operação de LPFC é a operação em regime de bateladas (LPBS). O problema 
é que LPBS têm uma alta demanda de oxigênio no início da sua operação, o que pode dificultar o estabelecimento de um ambiente aeróbio, necessário para a remoção eficiente do material orgânico. $O$ estabelecimento de um ambiente aeróbio na LPBS é facilitado por três fatores independentes: (1) no UASB remove-se grande parte dos sólidos suspenso e, portanto da turbidez, o que aumenta a taxa de fotossíntese; (2) como a concentração de material orgânico no afluente do UASB é baixa, a demanda de oxigênio para sua oxidação será reduzida; e (3) na medida em que a lagoa for mais rasa, a absorção de oxigênio atmosférico pela LPBS será maior e poderá fornecer oxigênio suficiente para atender à demanda na lagoa, mesmo sem haver produção de oxigênio pelas algas (fotossíntese).

No presente trabalho avaliou-se a possibilidade de usar lagoas de polimento operadas em regime de bateladas sequenciais (LPBS) para a remoção de material orgânico do efluente do reator UASB, bem como a influência da concentração inicial de material orgânico e da profundidade sobre o desempenho das LPBS.

\section{METODOLOGIA}

Os sistemas avaliados na presente pesquisa foram instalados e monitorados na Estação Experimental de Tratamento Biológico de Esgotos Sanitários (Extrabes), localizada na cidade de Campina Grande, Paraíba. O aparato experimental consistia em quatro lagoas de polimento alimentadas em regime de batelada sequencial, com profundidades de $20 \mathrm{~cm}, 40 \mathrm{~cm}, 60 \mathrm{~cm}$ e $100 \mathrm{~cm}$, com volumes de $40 \mathrm{~L}, 80 \mathrm{~L}, 120 \mathrm{~L}$ e $200 \mathrm{~L}$, respectivamente. As lagoas eram alimentadas com efluente de um reator UASB que recebia esgoto sanitário bruto advindo da rede coletora municipal. As LPBS possuíam misturadores que agitavam suavemente a fase líquida para manter um regime de mistura completa e evitar a flotação de algas. Na Fig. 1 é apresentado o sistema de tratamento experimental instalado.

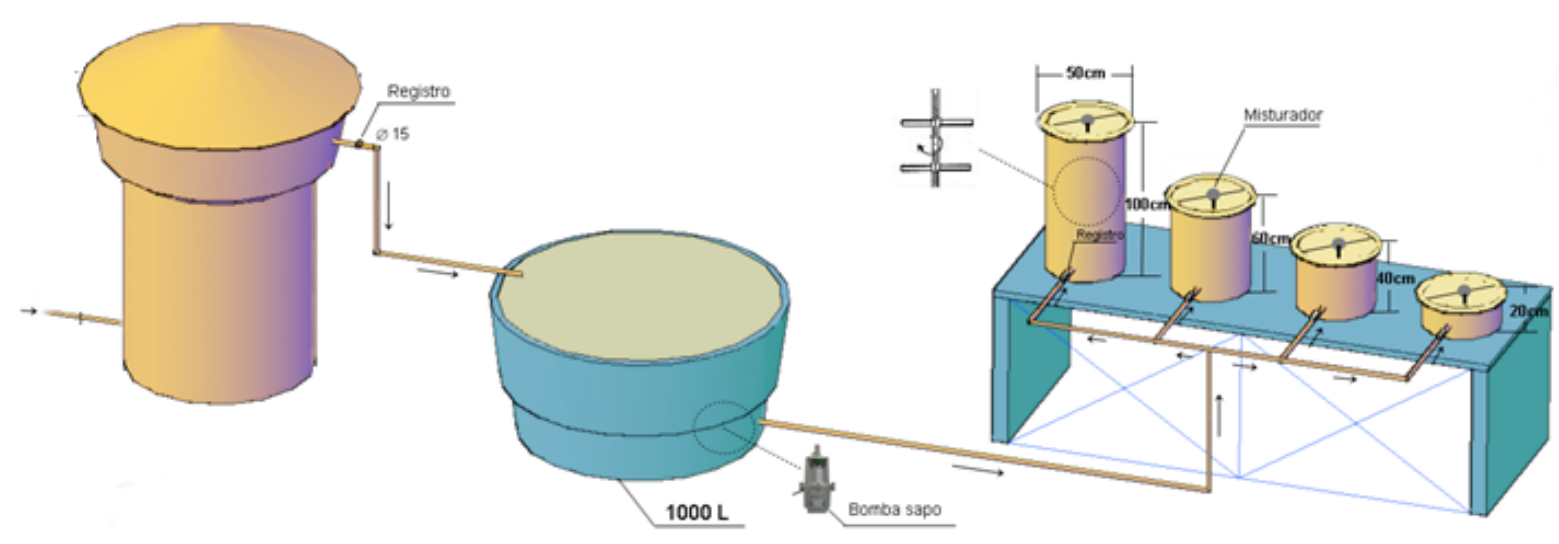

Figura 1 - Sistema de Tratamento de Esgoto Doméstico UASB-LPBC.

A pesquisa experimental se compôs de duas etapas: (1) eficiência da remoção de material orgânico do efluente de reatores UASB em LPBS e (2) limite de viabilidade de LPBS usando-se misturas de efluente do reator UASB e esgoto bruto para aumentar a concentração do material orgânico no início da operação das lagoas. 
Na primeira etapa da pesquisa, buscou-se acompanhar a eficiência da remoção da matéria orgânica e observar a elevação do oxigênio dissolvido e do $\mathrm{pH}$ na lagoa. Foram monitorados diariamente os parâmetros: $\mathrm{DBO}_{\text {total }}$ (Demanda Bioquími-

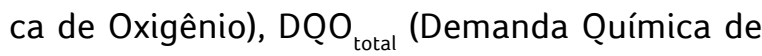
Oxigênio), OD (Oxigênio dissolvido) e $\mathrm{pH}$. As bateladas ocorreram em um tempo de 5 dias e foram realizadas um total de 7 bateladas para cada profundidade (de 0,2 a 1,0 m).

$\mathrm{Na}$ segunda etapa da pesquisa, verificou-se a influência da variação da carga orgânica sobre o desempenho das lagoas. Elevou-se a carga orgânica afluente por meio da adição de esgoto bruto ao efluente do reator UASB, nas seguintes proporções: $50 \%$, $80 \%$ e $100 \%$. Para cada uma das variações foram realizadas duas bateladas (repetições). Essa etapa da pesquisa foi realizada apenas para as lagoas de $20 \mathrm{~cm}$ e $40 \mathrm{~cm}$.

As análises $\mathrm{DBO}_{\text {total }}$ e $\mathrm{DQO}_{\text {total }}$ foram realizadas de acordo com as metodologias descritas no Standard Methods for the Examination of Water and Wastewater (APHA; AWWA; WEF, 2017). Os valores de $O D$ e $\mathrm{pH}$ foram determinados com o auxílio de uma sonda multiparamétrica (Hanna, modelo HI 98196).

\section{RESULTADOS E DISCUSSÃO}

\subsection{Remoção de material orgânico do efluente de reatores UASB em LPBS}

Nas Fig. 2 e 3, podem-se observar os valores médios da DBO e da DQ em função do tempo durante o tratamento nas LPBS para profundidades de 0,2, 0,4, 0,6 e 1,0 m. Em todos os casos foram utilizadas amostras brutas do conteúdo das lagoas para determinar os valores de DBO e DQO. Pode-se observar que os valores mínimos da DBO (20 mg/L) e DQO (100 mg/L) foram obtidos para a profundidade mínima de 0,2 m e tempo de per- manência de $2 \mathrm{~d}$. Para as maiores profundidades se obtiveram aproximadamente as mesmas concentrações mínimas para a DBO e a DQO , mas o tempo de permanência necessário era maior.

Os gráficos (Fig. 2 e 3) mostram que tanto os valores da DBO como os da DQO tendem a diminuir, inicialmente, passando por um mínimo e depois voltam a aumentar, chegando, inclusive, a valores superiores aos valores iniciais no efluente do UASB. Isso se deve ao crescimento de algas nas LPBS. Os valores da DQO são bem maiores que os da DBO para todas as profundidades e tempos de permanência, além de que a diferença entre ambos os parâmetros tende a aumentar com o tempo, indicando que há muito material não biodegradável no efluente, originado tanto do material inerte no efluente do UASB como da fração não biodegradável nas algas. Vários pesquisadores (CAVALCANTI, 2003; DIAS et al., 2014; HASAN et al., 2019) operando LPFC obtiveram resultados comparáveis da DBO e DQQO, embora com tempos de permanência mais longos do que na LPBS.
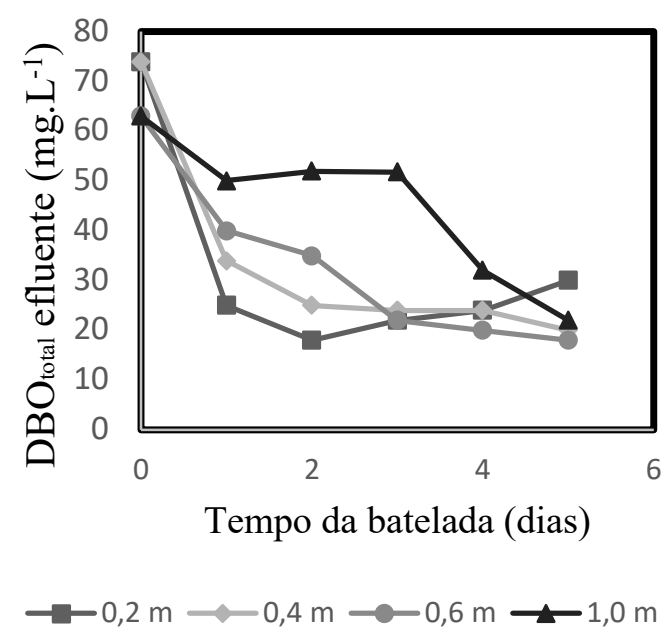

Figura 2 - Valor médio da DBO nas lagoas de 0,2, 0,4, 0,6 e 1,0 m de profundidade tratando efluente do reator UASB em função do tempo. 


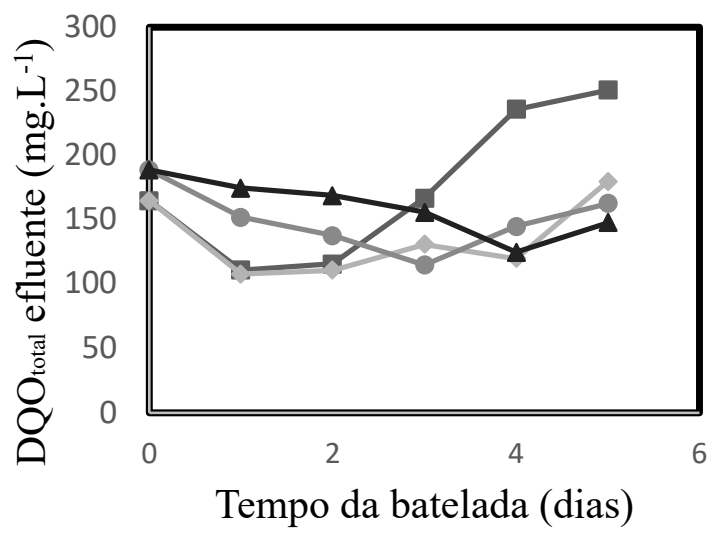

$\longrightarrow 0,2 \mathrm{~m} \longrightarrow 0,4 \mathrm{~m} \longrightarrow 0,6 \mathrm{~m} \rightarrow 1,0 \mathrm{~m}$

Figura 3 - Valor médio da DQQO nas lagoas de 0,2, 0,4, 0,6 e 1,0 m de profundidade tratando efluente do reator UASB em função do tempo.

Os valores mínimos da DBO na Fig. 2 são bem menores que os valores máximos permitidos pela Resolução Conama n 430/2011 para o efluente de lagoas de estabilização convencionais (BRASIL, 2011). A Resolução estabelece um máximo de $120 \mathrm{mg} / \mathrm{L}$, sendo que esse limite ainda poderá ser ultrapassado quando o efluente do sistema de tratamento atingir eficiência de remoção mínima de $60 \%$ de DBO, ou mediante estudo de autodepuração do corpo hídrico que comprove atendimento às metas do enquadramento do corpo receptor. $A$ Resolução Conama $n^{\circ}$ 430/2011 também indica que para a determinação da eficiência de remoção de carga poluidora em termos de $\mathrm{DBO}_{5,20}$ para sistemas de tratamento com lagoas, a amostra do efluente deverá ser filtrada. No entanto, neste trabalho realizaram-se os testes com amostra bruta e, apesar disso, os resultados obtidos foram abaixo dos 120 mg/L estipulados pela Resolução. Concluise que a DBO mínima do efluente bruto nas lagoas de polimento operadas em bateladas sequenciais para o pós-tratamento do efluente de reatores UASB é menor que o valor que os padrões brasileiros de lançamento. No que diz respeito à DQO, a supracitada Resolução não estabelece um padrão.
Nas Fig. 4 e 5 são apresentadas as médias da concentração de $\mathrm{OD}$ e do $\mathrm{pH}$ para as mesmas condições apresentadas nas Fig. 2 e 3. Em todos os casos, os valores de OD e do $\mathrm{pH}$ aumentaram com o tempo, mas à medida em que aumenta a profundidade da lagoa, o OD e pH aumentam mais lentamente. $O$ aumento da concentração $\mathrm{OD}$ e $\mathrm{pH}$ mostra claramente que a produção de oxigênio pelo processo de fotossíntese predominava sobre o consumo de oxigênio para a oxidação de material orgânico durante os testes e que essa predominância era mais acentuada nas lagoas de menor profundidade.

$\mathrm{O}$ valor do $\mathrm{pH}$ no efluente da LPBS tende a ser maior que o máximo permitido pela Resolução Conama $n^{\circ} 430 / 11$ quando o objetivo do tratamento é a remoção de nutrientes. Se isto é percebido como um problema, pode-se aplicar carbonatação do efluente usando o $\mathrm{CO}_{2}$ após a combustão do biogás. Essa carbonatação pode ser realizada em uma unidade específica ou então ser realizada na própria LPBS, especialmente quando o objetivo é acelerar a produção de algas.

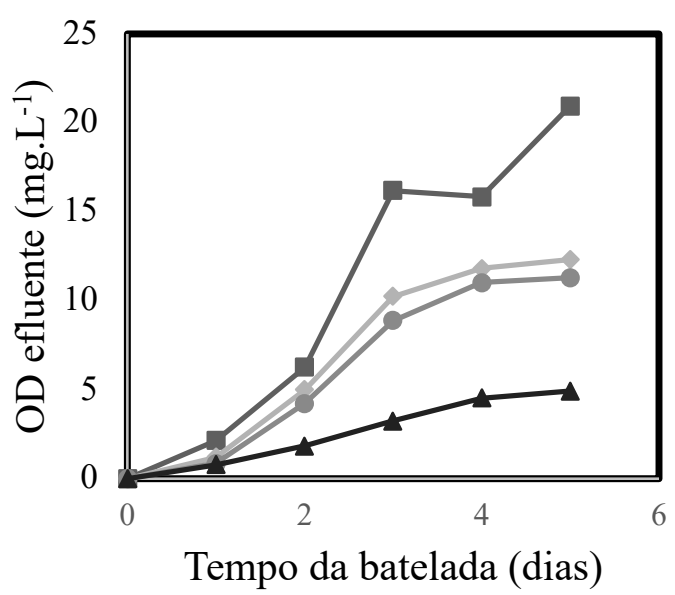

$\longrightarrow 0,2 \mathrm{~m} \longrightarrow 0,4 \mathrm{~m} \longrightarrow 0,6 \mathrm{~m} \longrightarrow 1,0 \mathrm{~m}$

Figura 4 - Valor da concentração de OD em função do tempo nas lagoas de 0,2, 0,4, 0,6 e 1,0 m de profundidade tratando efluente do reator UASB. 


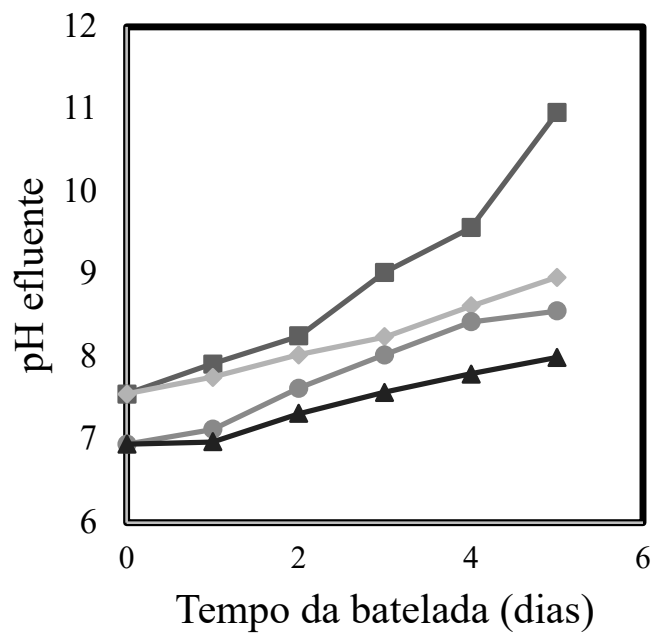

$\longrightarrow 0,2 \mathrm{~m} \longrightarrow 0,4 \mathrm{~m} \longrightarrow 0,6 \mathrm{~m} \longrightarrow 1,0 \mathrm{~m}$

Figura 5 - Valor do $\mathrm{pH}$ nas lagoas de 0,2, 0,4, 0,6 e 1,0 m de profundidade tratando efluente do reator UASB.

\subsection{Limite de viabilidade de LPBS}

O desempenho de lagoas de polimento com bateladas sequenciais foi avaliado para casos em que a concentração de material orgânico é mais alta que a do efluente do reator UASB. Nas Fig. 6 e 7 podem-se observar os valores médios da DBO em função do tempo durante o tratamento nas LPBS para profundidades de 0,2 e 0,4 m. Os dados mostram que houve redução da concentração de material orgânico ao longo do tempo, independentemente da concentração da DBO e da profundidade, entretanto as eficiências de remoção de DBO ao final da batelada diminuíram à medida em que $\mathrm{a}$ DBO do afluente da lagoa e $\mathrm{a}$ profundidade eram maiores.

As Fig. 8 e 9 mostram que há uma tendência de aumento da DQO ao longo do tratamento, semeIhante ao que ocorreu na Fig. 3, com efluente do UASB. Isso indica o desenvolvimento de algas no sistema e a produção de oxigênio dissolvido.
As Fig. 10, 11, 12 e 13 apresentam o aumento de OD e pH em LPBS com profundidade de 0,2 e 0,4 m. Pode-se observar que a concentração inicial de material orgânico tem uma influência muito forte sobre a evolução do OD e pH com o tempo. Isso se deve ao fato de a maior concentração de material orgânico aumentar a taxa de oxidação, resultando em menor produção de $\mathrm{OD}$ na lagoa e maior produção de $\mathrm{CO}_{2}$. Por essa razão, a concentração de OD e do pH aumenta menos à medida em que a concentração inicial de material orgânico é maior.

Como o aumento do $\mathrm{pH}$ é importante para a remoção de nutrientes, a concentração de material orgânico no afluente da LPBS deve ser baixa se a remoção de nutrientes é um dos objetivos do tratamento. Pode-se observar na Fig. 13 que somente a lagoa que trata apenas o efluente do reator UASB permite a obtenção de um $\mathrm{pH}$ de 9,5, necessário para a remoção de fósforo. Nos outros testes, com uma concentração mais elevada de material orgânico no afluente da LPBS, o pH final é menor, e isso significa que o aumento do $\mathrm{pH}$ é insuficiente para ter uma remoção eficiente de fosfato no efluente final.

As Fig. de 6 a 13 mostram claramente que o prétratamento anaeróbio eficiente é condição necessária para obter bons resultados na aplicação de LPBS. Nesse sentido, à medida que a concentração de material orgânico no afluente da LPBS aumenta, observa-se que a concentração de material orgânico no efluente final torna-se maior, enquanto a elevação do $\mathrm{pH}$ nas lagoas torna-se menor. $\mathrm{O}$ pH final mais baixo implica em uma remoção de nutrientes (especialmente a remoção de fosfato) menos eficiente. 


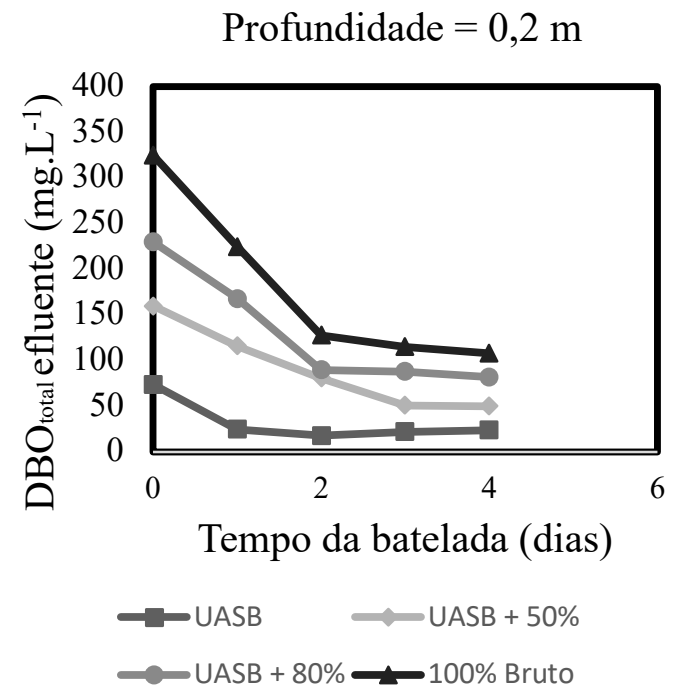

Figura 6 - Valor médio da DBO nas lagoas de 0,2 $\mathrm{m}$ de profundidade tratando efluente com diferentes valores da DBO no afluente.

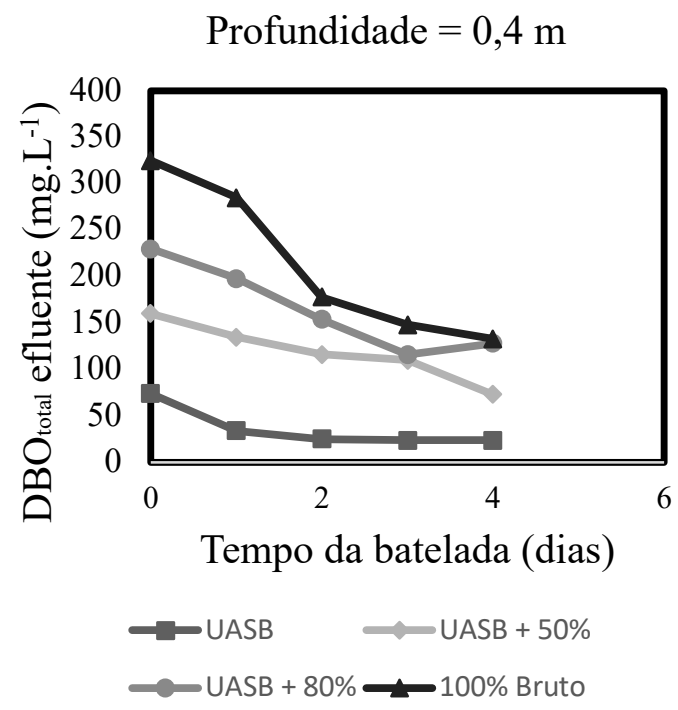

Figura 7 - Valor médio da DBO nas lagoas de 0,4 $\mathrm{m}$ de profundidade tratando efluente com diferentes valores da DBO no afluente.
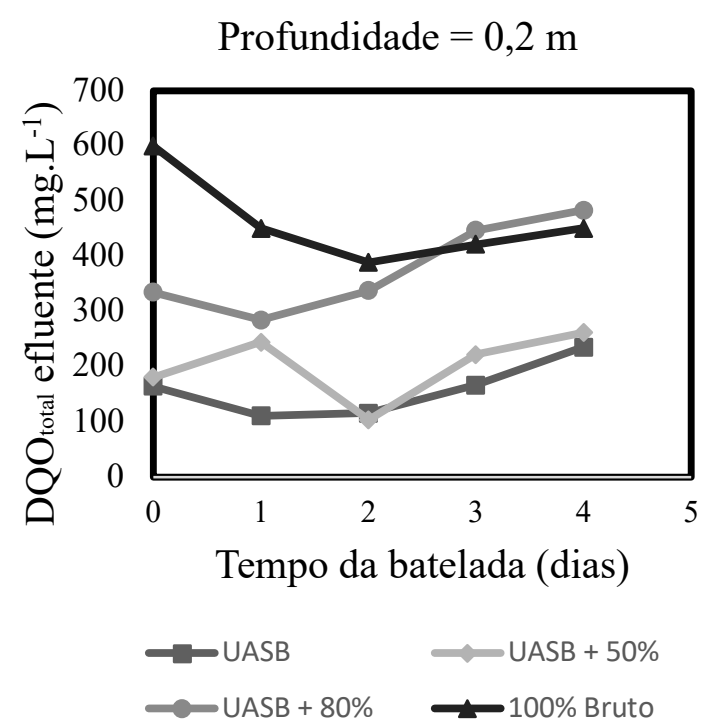

Figura 8 - Valor médio da DQQO nas lagoas de 0,2 $\mathrm{m}$ de profundidade tratando efluente com diferentes valores da DQQO no afluente.

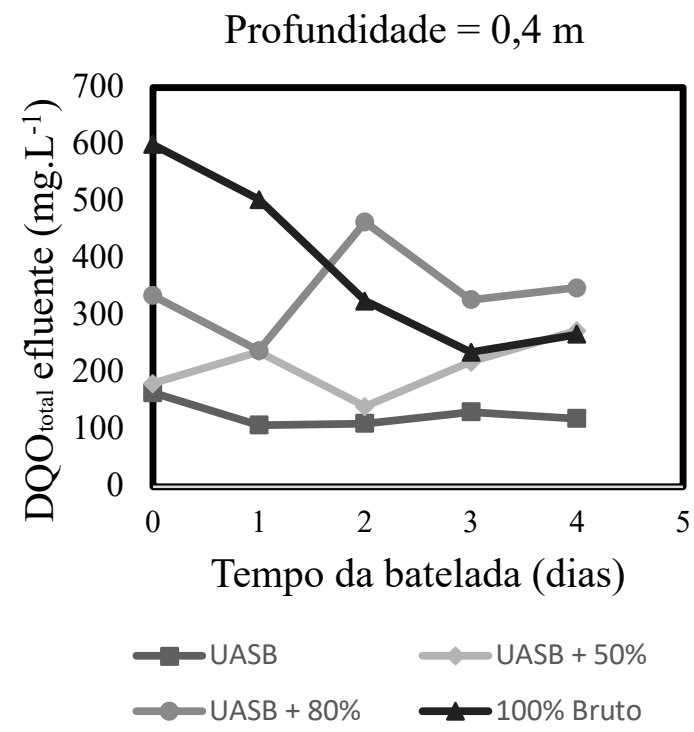

Figura 9 - Valor médio da DQQO nas lagoas de 0,4 m de profundidade tratando efluente com diferentes valores da DQQO no afluente. 


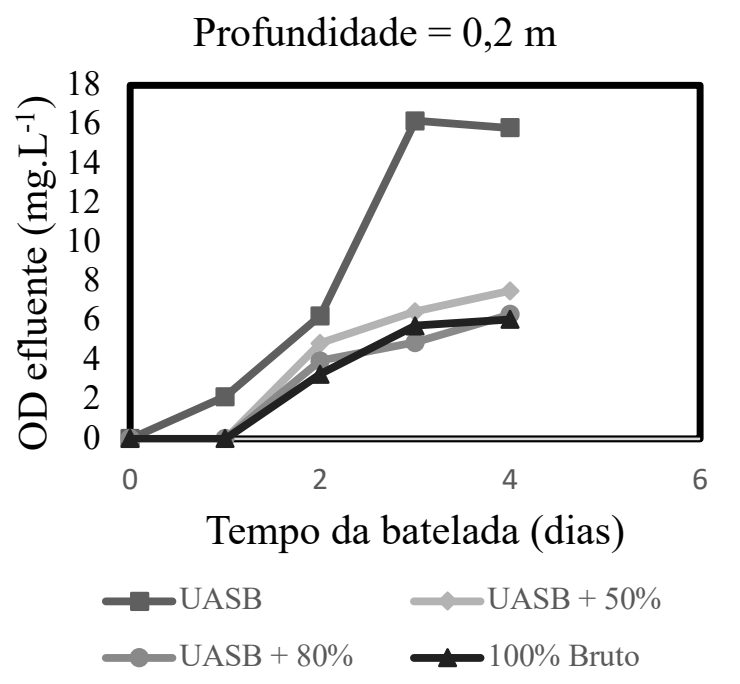

Figura 10 - Valor da concentração de OD em função do tempo com diferentes concentrações de material orgânico na lagoa de 0,2 de profundidade.

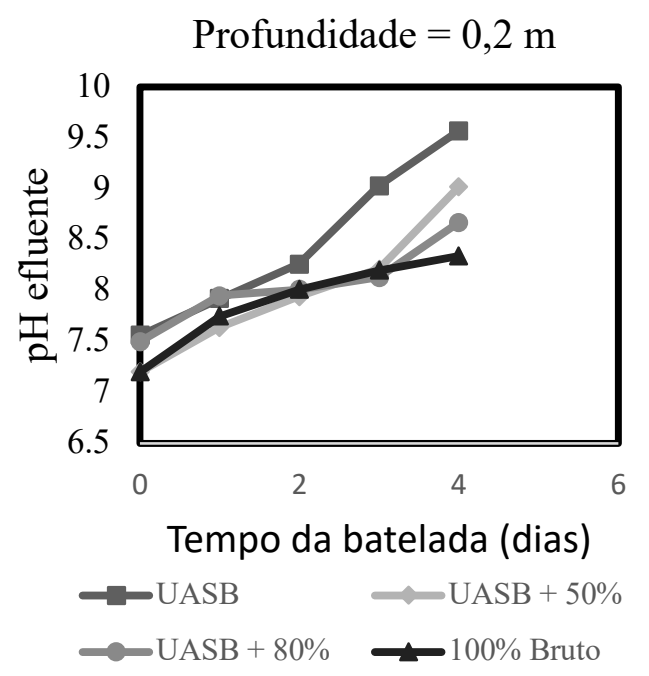

Figura 11 - Valor da concentração do pH em função do tempo com diferentes concentrações de material orgânico na lagoa de 0,2 de profundidade.

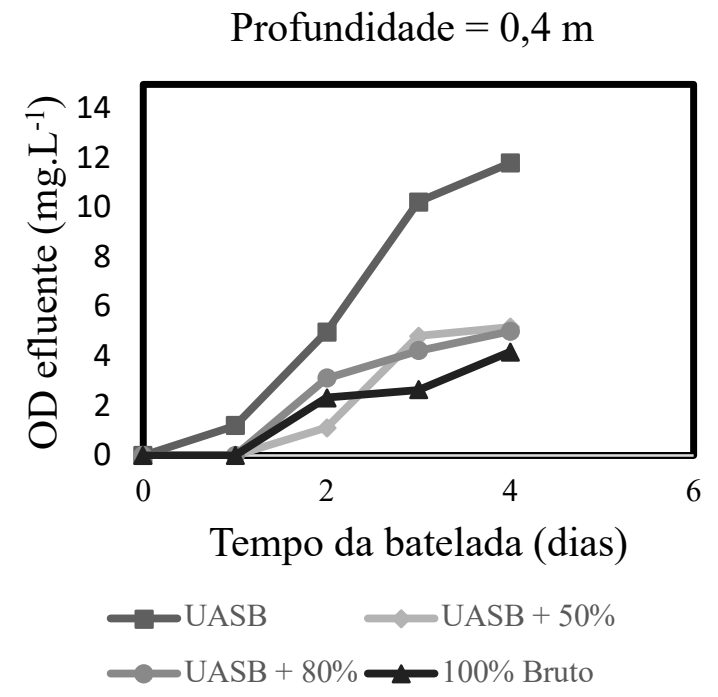

Figura 12 - Valor da concentração de OD em função do tempo com diferentes concentrações de material orgânico na lagoa de 0,4 de profundidade.

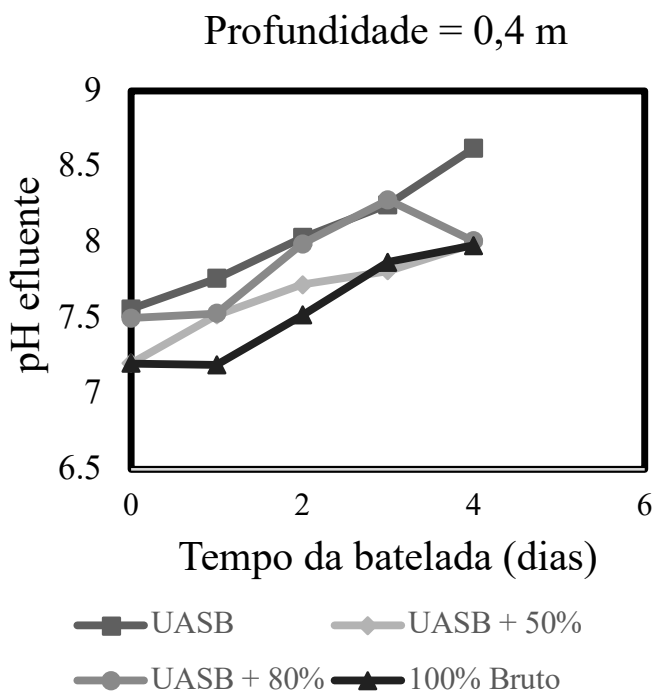

Figura 13 - Valor da concentração do pH em função do tempo com diferentes concentrações de material orgânico na lagoa de 0,4 de profundidade. 


\section{CONCLUSÕES}

A operação de lagoas de polimento em regime de bateladas sequenciais (LPBS) é factível e apresenta bom desempenho na remoção de material orgânico (DBO e DQO), possibilitando uma melhoria na qualidade do efluente final. $A \mathrm{DBO}_{\text {total }}$ do efluente final variou de 20 a 30 mg/L em um tempo de permanência de 2 a 4 dias para profundidades de 0,2 a $1,0 \mathrm{~m}$.

$\mathrm{Na}$ investigação experimental, a DBO do efluente final sempre foi menor que o padrão estabelecido pela resolução Conama ( $n^{\circ}$ 430/2011), mesmo tendo sido utilizadas para os testes amostras do efluente bruto e não efluente filtrado, como permitido pela norma.

Na prática da operação de LPBS pode não ser possível obter o valor mínimo da concentração de material orgânico, porque, para o tempo de permanência mais longo, que é necessário para remoção de nutrientes, a DBO e DQO tendem a aumentar devido ao crescimento de algas.

Ao elevar a concentração de material orgânico nas LPBS não se estabeleceu um ambiente anaeróbio nas lagoas e observou-se um aumento da concentração de OD e do $\mathrm{pH}$ com o tempo, embora menor para maiores profundidades e altas cargas aplicadas.

\section{AGRADECIMENTOS}

Os autores agradecem ao Conselho Nacional de Desenvolvimento Científico e Tecnológico (CNPq) pelo incentivo financeiro as pesquisas.

\section{CONTRIBUIÇÃO DOS AUTORES}

Todos os autores contribuíram de forma igualitária.

\section{REFERÊNCIAS}

AMERICAN PUBLIC HEALTH ASSOCIATION - APHA; AMERICAN WATER WORKS ASSOCIATION - AWWA; WATER ENVIRONMENT ASSOCIATION - WEF. Standard Methods for the Examination of Water and Wastewater. $23^{\text {th }}$. ed. Washington D C. 2017.
BASTOS R. K. X., CABRAL V. A. L., RIOS E. N., COMBATT M. P. M. (2014): Further contributions to nitrogen removal modelling in waste stabilization ponds Water Sci Technol 70 (12): 1897-1906

BRASIL. Conselho Nacional do Meio Ambiente. Resolução n 430, de 13 de maio de 2011. Dispõe sobre as condições e padrões de lançamento de efluentes, complementa e altera a Resolução n 357 , de 17 de março de 2005, do Conselho Nacional do Meio Ambiente - CONAMA.

BRASIL. Conselho Nacional do Meio Ambiente. Resolução n 357, de 17 de março de 2005. Dispõe sobre a classificação dos corpos de água e diretrizes ambientais para o seu enquadramento. CONAMA, 2005.

CAVALCANTI P. F. F. Integrated Application of the UASB Reactor and Ponds for Domestic Sewage Treatment in Tropical Regions. (PhD thesis) - University of Wageningen, The Netherlands, 2003.

CHERNICHARO, C. A. DE L. et al. Panorama do tratamento de esgoto sanitário nas regiões Sul, Sudeste e Centro-Oeste do Brasil: tecnologias mais empregadas. Revista DAE, v. 66, n. 213, p. 5-19, 2018. https://doi.org/10.4322/dae.2018.028

DIAS, D. F. C.; POSSMOSER-NASCIMENTO, T.E.; RODRIGUESV. A.J.;VON SPERLING, M. Overall performance evaluation of shallow maturation ponds in series treating UASB reactor effluent: Ten years of intensive monitoring of a system in Brazil. Ecological Engineering, v. 71, p. 206214, 2014. https://doi.org/10.1016/j.ecoleng.2014.07.044

GOMES, E.; PAING, J.; CASELLAS, C. E.; PICOT, B. Characterization of phosphorus in sediments of waste stabilization ponds. Water Sci Technol v. 42, p. 257-264, 2000.

HASAN, M. N.; KHAN, A. A.; AHMAD, S.; LEW, B. Anaerobic and aerobic sewage treatment plants in Northern India: Two years intensive evaluation and perspectives. Environmental Technology \& Innovation, v. 15, p. 10, 2019. https://doi.org/10.1016/j.eti.2019.100396

MARA, D. D. Proposed design for oxidation ponds in hot climates. J. Environ. Eng. Division-Asce, v. 101, p. 296-300, 1976.

MARAIS, G. V. R. Fecal Bacterial Kinetics in Stabilization Ponds. Journal of the Environmental Engineering Division, v. 100, n. 1, p. 119-139, 1974.

MARAIS, G. V. R.; SHAW, V. A. A RATIONAL THEORY FOR THE DESIGN OFSEWAGE STABILIZATION PONDS IN CENTRAL AND SOUTH AFRICA. Transactions of the South African Inst. of Civil Eng., v. 3, n. 11, p. 205, 1961.

PANO, A.; MIDDLEBROOKS, E. J. Ammonia Nitrogen Removal in Facultative Wastewater Stabilization Ponds. Water Pollution Control Federation, v. 54, n. 4, p. 344-351, 1982. https://doi. org/10.2307/25041312

PARKER, C. D.; JONES, H. L.; TAYLOR, W. S. Purification of Sewage in Lagoons. Sewage and Industrial Waste, v. 22, n. 6, p. 760-775, 1950. https://doi.org/10.2307/25031317

VAN HAANDEL A. C.; VAN DER LUBBE J. Anaerobic sewage digestion: Theory and applications. International Water Association Londres RU. 2019. 